\title{
Morfoanatomia do sistema subterrâneo de Smallanthus sonchifolius (Poepp. \& Endl.) H. Robinson (Asteraceae)
}

\author{
SILVIA R. MACHADO ${ }^{1,3}$, DENISE M.T. OLIVEIRA, MARÍCIA R. DIP ${ }^{1}$ e NANUZA L. MENEZES²
}

(recebido: 15 de maio de 2002; aceito: 20 de novembro de 2003)

\begin{abstract}
Morphology and anatomy of the underground system of Smallanthus sonchifolius (Poepp. \& Endl.) H. Robinson (Asteraceae)). Smallanthus sonchifolius (Poepp. \& Endl.) H. Robinson (Asteraceae), known as yacon is a highaltitude tropical herbaceous species. It was introduced into several countries, including Brazil, because of its nutritional potential, high yield but mainly as a source of inulin. Although its agronomy and biochemistry are relatively well established, little is known about the morphology and nature of its underground system, the main inulin source. The underground system is heterogeneous in nature, consisting of rhizophores, and adventitious thin and tuberous roots. The rhizophores and roots present secretory ducts of lipid in the inner cortical layers, which is derived from the meristematic endoderm.
\end{abstract}

Key words - meristematic endoderm, rhizophore, secretory ducts, Smallanthus sonchifolius, tuberous roots

RESUMO - (Morfoanatomia do sistema subterrâneo de Smallanthus sonchifolius (Poepp. \& Endl.) H. Robinson (Asteraceae)). Smallanthus sonchifolius (Poepp. \& Endl.) H. Robinson (Asteraceae), conhecida como yacon, é uma espécie herbácea de clima tropical de altitude, tendo sido introduzida em diversos países, incluindo o Brasil, devido ao seu potencial alimentício, forrageiro e, principalmente, como substrato para a produção de inulina. Embora aspectos agronômicos e bioquímicos desta planta sejam relativamente conhecidos, pouco se sabe a respeito da morfologia e natureza do sistema subterrâneo, principal fonte de inulina. Verificou-se que o sistema subterrâneo tem natureza mista, sendo constituído por rizóforos e raízes delgadas e tuberosas, ambas adventícias. Canais secretores de substâncias lipídicas estão presentes nos rizóforos e raízes; nestas, os canais originam-se nas camadas corticais internas derivadas da endoderme meristemática.

Palavras-chave - canais secretores, endoderme meristemática, raiz tuberosa, rizóforo, Smallanthus sonchifolius

\section{Introdução}

Smallanthus sonchifolius Poepp. \& Endl. (Asteraceae, Asteroideae, Heliantheae) é uma espécie herbácea de clima tropical de altitude, tendo sido introduzida em diversos países, incluindo o Brasil, devido ao seu potencial alimentício, forrageiro e, principalmente, como fonte de inulina concentrada nos órgãos subterrâneos (National Research Council 1989, Fukai et al. 1993).

Conhecida como yacon, a espécie apresenta sistema subterrâneo complexo, não havendo consenso sobre a denominação dos órgãos que o compõem. Assim, encontram-se referências a tubérculo (Asami et al. 1989, 1991, Hawkes 1989, Ohyama et al. 1990, Wei et al. 1991, Kakuta et al. 1992, Estrella \& Lazarte 1994), a caule rizomatoso (National Research Council 1989),

\footnotetext{
1. Universidade Estadual Paulista, Instituto de Biociências, Departamento de Botânica, Caixa Postal 510, 18618-000 Botucatu, SP, Brasil.

2. Universidade de São Paulo, Instituto de Biociências, Departamento de Botânica, Caixa Postal 11461, 05422-970 São Paulo, SP, Brasil.

3. Autor para correspondência: smachado@ibb.unesp.br
}

rizoma simpodial (Grau \& Rea 1997), a raiz tuberosa (Leon 1968, Nieto 1991, Grau \& Rea 1997), a raiz comestível e tuberosa (Bonucceli 1989), ou, como em Zardini (1991), rizoma lenhoso, rizoma carnoso e raiz de reserva.

As raízes de Smallanthus sonchifolius, assim como os caules, apresentam grande quantidade de inulina, frutano de baixa caloria com elevado potencial dietético, podendo ser um substituto natural do açúcar na alimentação de diabéticos (National Research Council 1989, Figueiredo-Ribeiro et al. 1992, Fukai et al. 1993).

Embora alguns aspectos agronômicos (Nieto 1991, Estrella \& Lazarte 1994) e bioquímicos (Ohyama et al. 1990, Asami et al. 1991, Wei et al. 1991, Fukai et al. 1993) desta planta sejam relativamente conhecidos, pouco se sabe a respeito da morfologia e natureza do sistema subterrâneo.

Visando a elucidar a natureza dos órgãos subterrâneos de Smallanthus sonchifolius, principalmente dos responsáveis pela propagação vegetativa e daqueles que apresentam reserva de frutanos, este trabalho teve por objetivo caracterizar a morfologia e anatomia dos órgãos que compõem o sistema subterrâneo. 


\section{Material e métodos}

O material foi coletado de exemplares de Smallanthus sonchifolius (sinônimos: Polymnia sonchifolia Poepp. \& Endl. e P. edulis Wedd.) cultivados em canteiros experimentais na Faculdade de Ciências Agronômicas da Universidade Estadual Paulista, Câmpus de Botucatu, São Paulo, Brasil. O cultivo vem sendo feito por meio de propagação vegetativa, a partir de fragmentos do sistema subterrâneo contendo gemas, obtidos de plantas adultas. Após a confirmação da identificação da espécie, as exsicatas foram depositadas no Herbário BOTU, sob o número 20.414.

As observações morfológicas foram feitas em material fresco ou estocado em Etanol 70\%. As ilustrações foram preparadas em câmara clara acoplada a estereomicroscópio Zeiss e câmara fotográfica Pentax.

Para análise anatômica, amostras foram fixadas na mistura de Karnovsky (Karnovsky 1965). Lâminas semipermanentes foram preparadas com secções obtidas a mão livre, coradas com 5\% de solução aquosa de Safranina 1\% e 95\% de solução aquosa de Azul de Astra 1\%. Confeccionaram-se, também, lâminas permanentes a partir de material incluído em glicol-metacrilato, sendo as secções coradas com solução aquosa de Azul de Toluidina 0,05\%, pH 4,7 (O’Brien et al. 1964).

Para verificação da presença de substâncias lipofílicas, secções de material fresco foram submetidas a tratamento com Sudan IV (Johansen 1940).

Os aspectos anatômicos mais relevantes foram ilustrados em fotomicroscópio Zeiss.

\section{Resultados}

A planta apresenta eixos aéreos, com folhas e gemas vegetativas e florais, e um sistema subterrâneo espessado de natureza mista representado por rizóforos e raízes (figuras 1-6). Todo o sistema radicular é formado por raízes adventícias, sendo que algumas permanecem delgadas e outras sofrem intensa tuberificação (figuras $1,3,6)$. As raízes tuberosas são inicialmente fusiformes, adquirindo formas irregulares e variáveis na maturidade.

Os rizóforos são estruturas cônicas, tenras e ligeiramente espessadas, cujo ápice tem coloração esbranquiçada; exibem nós e entrenós nítidos, além de inúmeras gemas protegidas por catafilos (figuras 1,2). Freqüentemente, ainda ligados à planta-mãe, podem originar vários ramos aéreos simultaneamente, resultando na formação de touceiras (figura 4). $\mathrm{Na}$ época do brotamento, os nós distais do rizóforo apresentam coloração rósea e os proximais são castanhos (figuras $4,6)$. As gemas originam ramos caulinares aéreos eretos (figuras 4, 10) e novos rizóforos (figuras 1, 4, 6). Primórdios de raízes adventícias são observados em torno da base de cada entrenó dos rizóforos (figuras 5, 10 ), originando raízes delgadas (figura 7) e raízes tuberosas (figuras 6, 8-10).

As raízes delgadas apresentam epiderme unisseriada, com pêlos radiculares (figura 11). O córtex é formado por cerca de 15 camadas de células parenquimáticas, com exoderme distinta (figura 11); no córtex interno, as células têm caracteristicamente disposição radial (figuras 11, 12) e são resultantes da endoderme meristemática. Nesta região, ocorrem canais secretores constituídos por lume losangular (figuras 12-14); no lume, foram detectadas gotas de lipídios (figuras 15, 16). A camada cortical mais interna é uma endoderme típica, com estrias de Caspary conspícuas (figuras 13, 14). O cilindro vascular é um protostelo que varia de tetrarco a poliarco, com parênquima medular evidente (figuras 11, 12).

As raízes tuberosas apresentam periderme pouco desenvolvida, com lenticelas evidentes (figura 17). O córtex interno tem origem endodérmica e as células, dispostas radialmente, mostram numerosas divisões anticlinais e periclinais (figuras 17,18 ) que levam ao aumento do diâmetro desse órgão. Nas camadas corticais adjacentes à endoderme, originam-se canais secretores: entre duas células da endoderme e duas células da camada adjacente externa, nota-se a formação de um espaço losangular conspícuo, de origem esquizógena, que acumula substâncias lipídicas. Estes espaços formam-se em toda a periferia da endoderme e são delimitados por epitélio secretor uniestratificado, constituído por quatro células (figuras 18, 19). Posteriormente, por divisões desiguais e sempre no plano oblíquo destas quatro células, originam-se novas células

Figures 1-6. S. sonchifolius. 1. General view of the adult plant's underground system showing many rhizophores (rz) and thin roots (rd) and tuberous (rt). 2. Detail of a rhizophores connected to the mother plant; note the cataphyll (arrow). 3. Young plant underground system with thin roots and tuberous and developing rhizophores (arrow), producing roots at the base of internode; note the base of the aerial stem (ca). 4. Sprouts produced from rhizophores connected to mother plant. 5. Rhizophores detail at shooting time, with proliferation of buds (*) and primordia of adventitious roots (arrowhead). 6 . A plant underground system produced from a rhizophores with thin roots and in the process of tuber formation. Bars $=2 \mathrm{~cm}(5) ; 1 \mathrm{~cm}(1,3,4,6) ; 5 \mathrm{~mm}$ (2). 



Figuras 1-6. S. sonchifolius. 1. Aspecto geral do sistema subterrâneo de planta adulta, mostrando inúmeros rizóforos (rz) e raízes delgadas (rd) e tuberosas (rt). 2. Detalhe de um rizóforo ligado à planta-mãe; observar catafilo (seta). 3. Sistema subterrâneo de planta jovem, com raízes delgadas (rd) e tuberosas (rt) e rizóforos (seta) em desenvolvimento, produzindo raízes na base do entrenó; notar a base do caule aéreo (ca). 4. Rebrota produzida a partir de rizóforos ligados à planta-mãe. 5. Detalhe do rizóforo na época do brotamento, com proliferação de gemas $(*)$ e primórdios de raízes adventícias (ponta de seta). 6. Sistema subterrâneo de indivíduo produzido a partir de um rizóforo, com raízes delgadas e em processo de tuberização. Barras $=2 \mathrm{~cm}(5) ; 1 \mathrm{~cm}(1,3$, $4,6) ; 5 \mathrm{~mm}(2)$. 


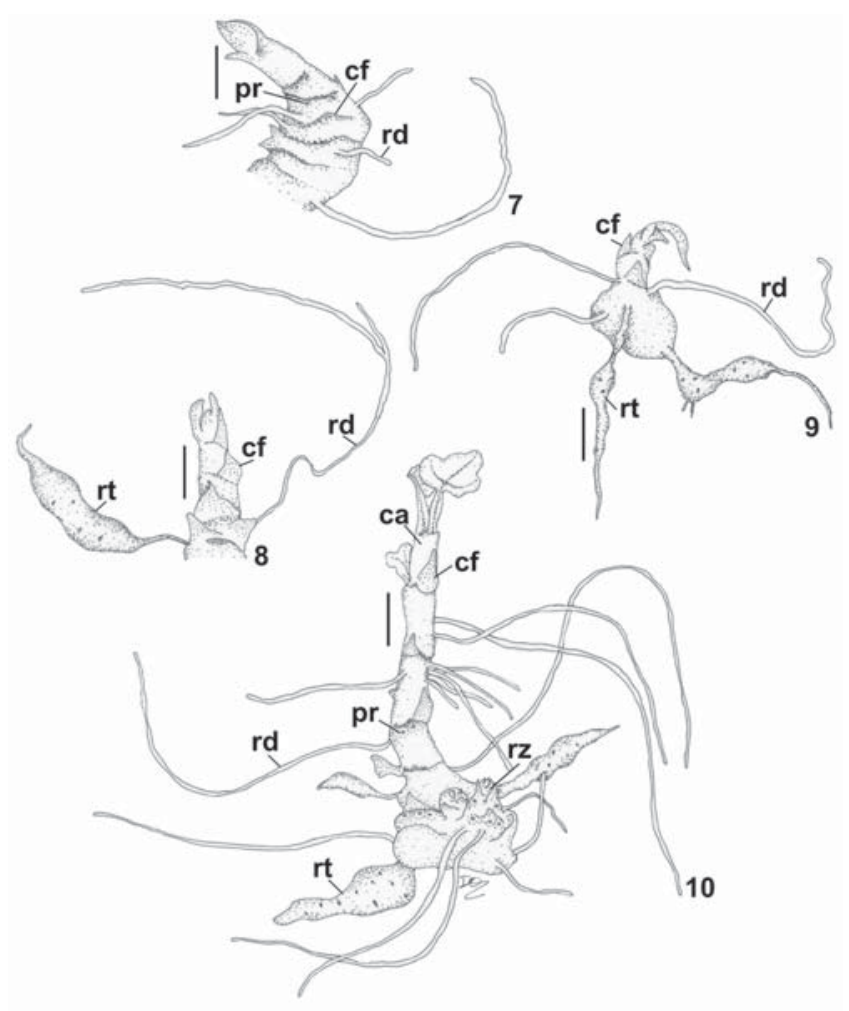

Figuras 7-10. Estágios sucessivos do desenvolvimento de plantas de S. sonchifolius, a partir de fragmento do rizóforo contendo gemas e primórdios de raízes adventícias. $(\mathrm{ca}=$ caule aéreo, $\mathrm{cf}=$ catafilo, $\mathrm{pr}=$ primórdio de raiz adventícia, $\mathrm{rd}=$ raiz delgada, $\mathrm{rt}=$ raiz tuberosa, $\mathrm{rz}=$ rizóforo). Barras $=1 \mathrm{~cm}$.

Figures 7-10. Successive development stages of S. sonchifolius, from rhizophores fragment containing buds and primordia of adventitious roots. (ca = aerial stem, $\mathrm{cf}=$ cataphyll, $\mathrm{pr}=$ adventitious root primordia, $\mathrm{rd}=$ thin root, $\mathrm{rt}=$ tuber root, $\mathrm{rz}=$ rhizophores). Bars $=1 \mathrm{~cm}$.

epiteliais (figura 20). Em secção transversal, os canais maduros mostram lume tendendo a circular e número variável de estratos de células epiteliais (figura 21). O estelo é poliarco, com extenso parênquima medular, ocorrendo atividade cambial irregular (figuras 17, 18).

Nos rizóforos, o ápice apresenta epiderme unisseriada e córtex com aproximadamente seis camadas de células parenquimáticas com divisões anticlinais; nesta região, ocorrem canais secretores (figura 23). Nas camadas subepidérmicas, nota-se o felogênio em início de implantação (figura 23). O sistema vascular é representado por feixes colaterais, com extensa região de parênquima interfascicular, dispostos em um anel em torno de ampla medula (figura 22).

Na região proximal, o rizóforo apresenta periderme com lenticelas (figuras 24, 25); córtex mais amplo que o da região distal, com numerosos canais secretores; os feixes vasculares apresentam câmbio incipiente (figura 24) e rodeiam ampla medula onde também se observam canais secretores.

Em todo o rizóforo, o sistema fundamental exibe divisões celulares em planos variados (figuras 23-25), mais freqüentes na região proximal, resultando no aumento de espessura observado.

\section{Discussão}

A presença de um sistema caulinar subterrâneo ramificado, formando raízes adventícias tuberosas e delgadas, em Smallanthus sonchifolius foi relatada por Grau \& Rea (1997), que o denominaram rizoma simpodial. Neste trabalho, as observações realizadas demonstraram que a estrutura caulinar subterrânea é um rizóforo, que origina raízes delgadas, raízes tuberosas e numerosas gemas caulinares. Estas darão origem a ramos aéreos e a novos rizóforos.

A ocorrência de rizóforos tem sido registrada em diferentes táxons (Sajo \& Menezes 1986b, Rocha \& Menezes 1997, Andreata \& Menezes 1999), incluindo representantes da família Asteraceae. Em espécies de Vernonia (Sajo \& Menezes 1986b), foi demonstrado ser o rizóforo um sistema caulinar subterrâneo portador de raízes, com gemas apical e laterais, que se origina do nó cotiledonar. Após a formação, a partir do nó cotiledonar, dos dois primeiros rizóforos com crescimento geotrópico positivo, a raiz primária degenera e todo o sistema de raízes é adventício.

Em Smilax (Smilacaceae), uma monocotiledônea, verificou-se processo similar, com a formação de um único rizóforo no nó cotiledonar (Andreata \& Menezes 1999).

Em Dioscorea kunthiana Uline ex Knuth (Dioscoreaceae), Rocha \& Menezes (1997) descreveram o rizóforo como um segundo sistema caulinar que a planta apresenta, com crescimento geotrópico positivo. É importante ressaltar que Goebel (1905) refere-se ao órgão subterrâneo em Dioscoreaceae como sendo homólogo ao órgão portador de raízes de Selaginella.

A proliferação de gemas levando à formação de touceiras em Smallanthus sonchifolius revela o potencial do rizóforo como órgão de reserva e de propagação vegetativa, como já ressaltado por Sajo \& Menezes (1986a).

Anatomicamente, o rizóforo de Smallanthus sonchifolius caracteriza-se por apresentar espessamento produzido por tecido parenquimático de 

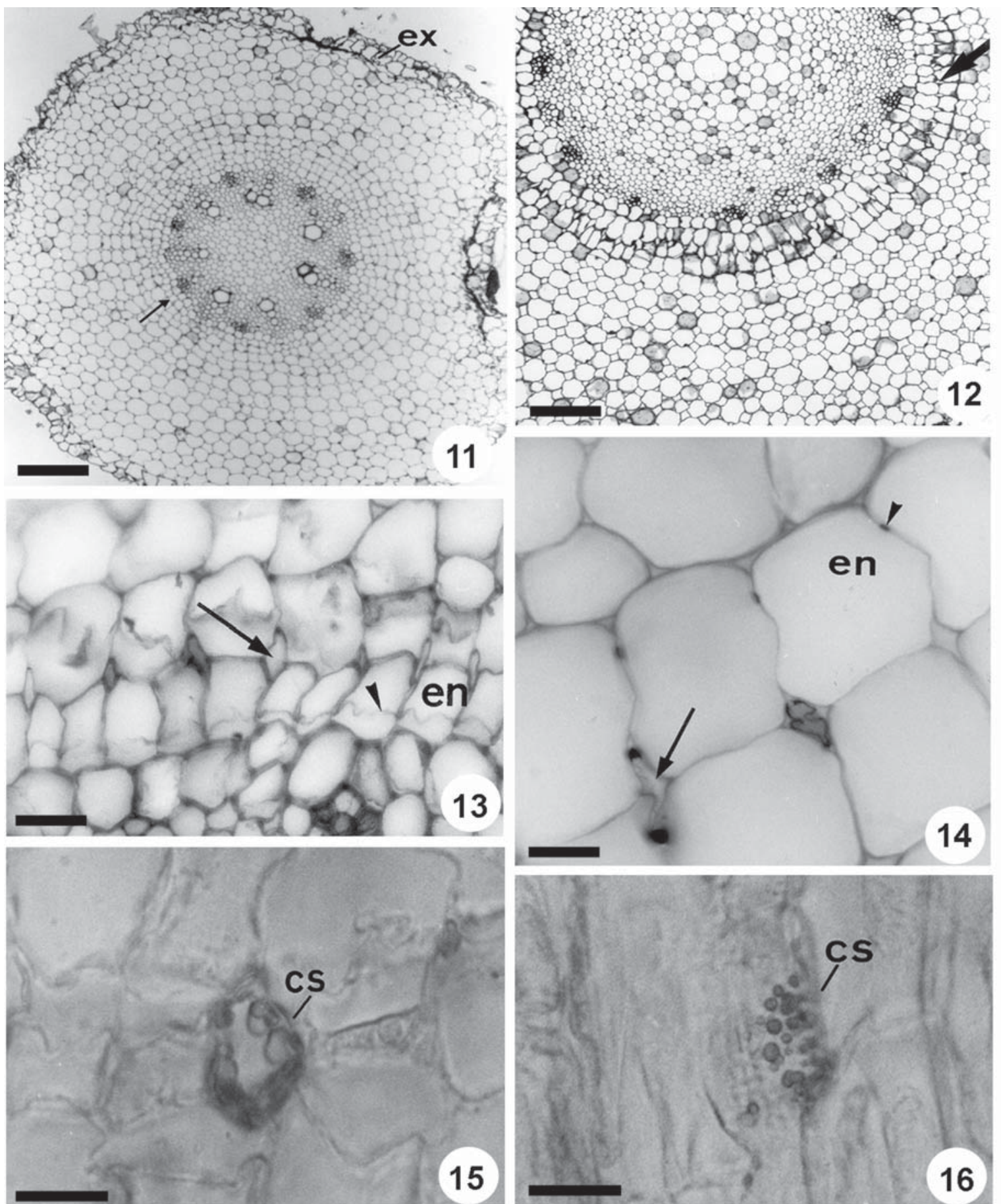

Figuras 11-16. Raízes delgadas de S. sonchifolius. 11-15. Secções transversais. 16. Secção longitudinal. 11. Raiz poliarca, mostrando pêlos radiculares, a exoderme (ex) e o córtex interno com células dispostas radialmente (seta). 12. Início de formação de canais secretores adjacentes à endoderme (seta). 13-14. Detalhes da endoderme (en) e dos canais com lume losangular (seta); a ponta de seta indica estria de Caspary. 15-16. Lume de canal secretor (cs) contendo gotas de lipídios. Barras $=100 \mu \mathrm{m}$ $(11,12) ; 25 \mu \mathrm{m}(13) ; 20 \mu \mathrm{m}(16) ; 10 \mu \mathrm{m}(14,15)$.

Figures 11-16. S. sonchifolius thin root. 11-15. Transverse sections. 16. Longitudinal section. 11. Polyarch root, showing radicular hairs, exodermis (ex), and the inner cortex with radially arranged cells (arrow). 12. Beginning of formation of secretory ducts adjacent to the endodermis (arrow). 13-14. Details of endodermis (en) and ducts with lozenge lumen (arrow); arrowhead indicates Casparian strip. 15-16. Secretory duct (cs) lumen containing oil drops. Bars $=100 \mu \mathrm{m}(11,12) ; 25 \mu \mathrm{m}(13) ; 20 \mu \mathrm{m}(16)$; $10 \mu \mathrm{m}(14,15)$. 
origem fundamental, o que difere do rizóforo das espécies de Vernonia estudadas por Sajo \& Menezes (1986a), onde o crescimento em espessura se deve à proliferação de parênquima adicional proveniente de câmbios acessórios no interior do xilema secundário.

Com relação às diversas denominações atribuídas ao órgão espessado e comestível, principal fonte de frutanos de Smallanthus sonchifolius, justifica-se apenas a utilização de raiz tuberosa (Leon 1968, Bonucceli 1989, Nieto 1991, Grau \& Rea 1997). O estudo anatômico evidenciou claramente que a organização do sistema vascular deste órgão é típica de
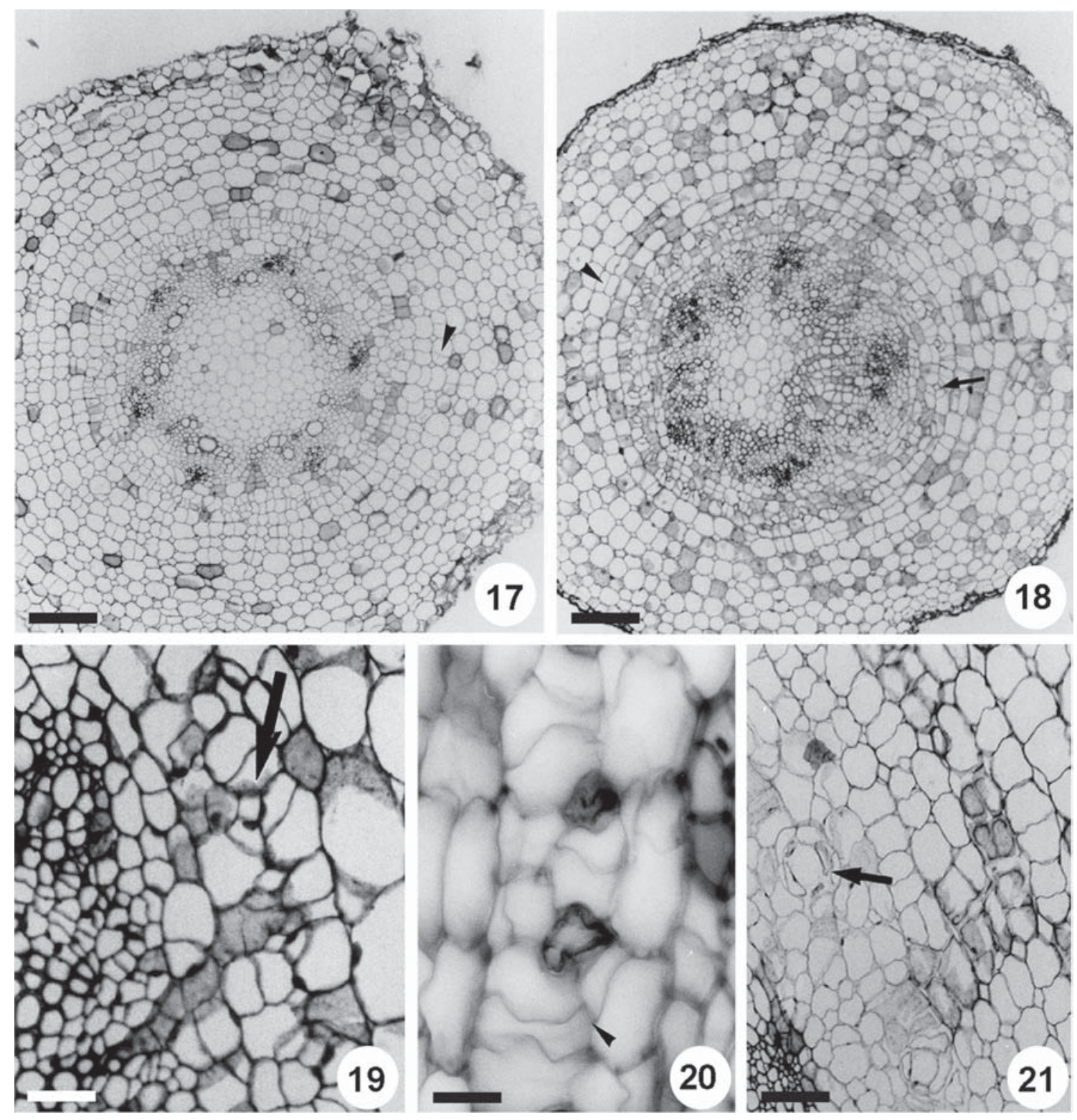

Figuras 17-21. Secções transversais de raízes tuberosas de S. sonchifolius. 17-18. Aspecto geral de raiz em início de espessamento, mostrando a disposição radial e numerosas divisões das células corticais internas (ponta de seta); seta indica canal secretor. 19. Detalhe da figura anterior, mostrando o início da formação de canais secretores endodérmicos (seta). 20. Detalhe do canal em desenvolvimento, com proliferação de células epiteliais (ponta de seta). 21. Canais secretores diferenciados (seta). Barras $=200 \mu \mathrm{m}(17,18) ; 100 \mu \mathrm{m}(21) ; 50 \mu \mathrm{m}(19) ; 25 \mu \mathrm{m}(20)$.

Figures 17-21. S. sonchifolius tuberous root transverse sections. 17-18. General view of root at beginning of thickening showing radial arrangement and many inner cortical cell divisions (arrowhead); arrow indicates secretory ducts. 19. Detail of the previous figure showing the beginning of endodermic secretory duct formation (arrow). 20. Detail of the developing duct with epithelial cell proliferation (arrowhead). 21. Differentiated secretory ducts (arrow). Bars $=200 \mu \mathrm{m}(17,18) ; 100 \mu \mathrm{m}(21)$; $50 \mu \mathrm{m}(19) ; 25 \mu \mathrm{m}$ (20). 
raiz. As referências na literatura a tubérculo e rizoma não são adequadas, uma vez que estes são órgãos subterrâneos de natureza caulinar.

No que se refere à anatomia da raiz, verificou-se a presença de uma endoderme meristemática responsável pela formação de várias camadas de células do córtex interno, as quais mostram disposição radial característica. Nas raízes delgadas, as células das camadas resultantes da endoderme meristemática sofrem apenas divisões periclinais. Nas raízes que se tuberificam, observam-se divisões anticlinais, além das periclinais. $\mathrm{O}$ papel meristemático da endoderme na
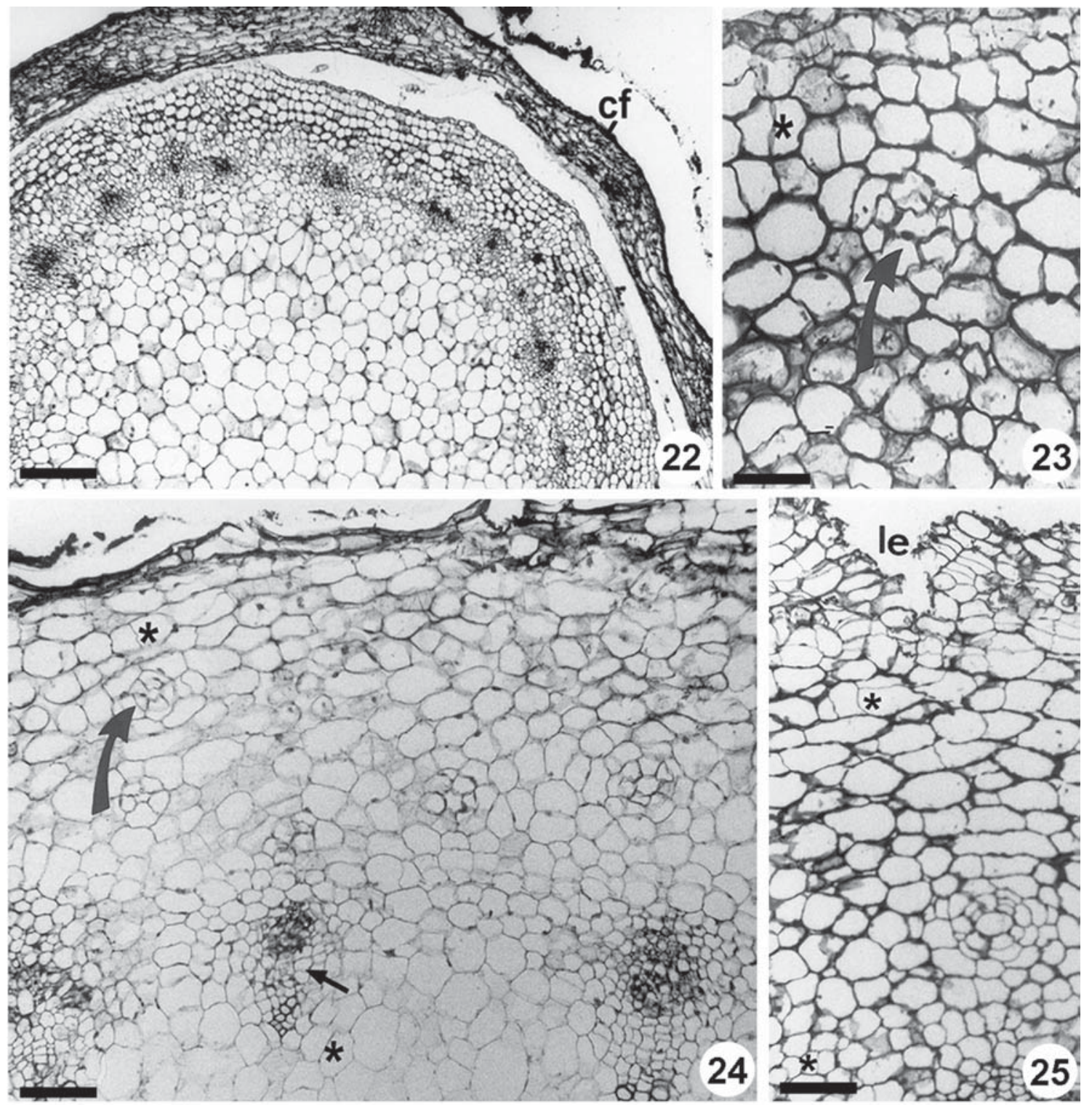

Figuras 22-25. Secções transversais do rizóforo de S. sonchifolius. 22. Porção distal, mostrando o córtex reduzido, feixes colaterais dispostos em círculo e medula ampla $(\mathrm{cf}=$ catafilo). 23. Detalhe da figura anterior, mostrando o felogênio subepidérmico (seta) e canal secretor (seta curva); * = divisão celular. 24-25. Região proximal, mostrando periderme com lenticela (le), canais secretores (seta curva) no córtex e medula, e feixes vasculares com câmbio fascicular (seta); ${ }^{*}=$ divisão celular. Barras $=200 \mu \mathrm{m}$ (22); $100 \mu \mathrm{m}(24,25) ; 50 \mu \mathrm{m}(23)$.

Figures 22-25. S. sonchifolius rhizophores transverse sections. 22. Distal portion showing the reduced cortex, collateral bundles arranged in a circle, and wide pith ( $\mathrm{cf}=$ cataphyll). 23. Detail of the previous figure showing the subepidermal phellogen (arrow) and secretory duct (curved arrow); ${ }^{*}=$ cell division. 24-25. Proximal region showing peridermis with lenticell (le), secretory ducts (curved arrow) in the cortex and pith, and vascular bundles with fascicular cambium (arrow); ${ }^{*}=$ cell division. Bars $=200 \mu \mathrm{m}(22) ; 100 \mu \mathrm{m}(24,25) ; 50 \mu \mathrm{m}(23)$. 
produção das células do córtex interno da raiz foi registrado por Williams (1947), Van Fleet (1961), Mueller (1991), Seago \& Scholey (1999), Seago et al. (1999) e Melo-de-Pinna \& Menezes (2002).

O aumento de espessura das raízes tuberosas é resultante da proliferação de tecido parenquimático, como já destacado por Grau \& Rea (1997). Segundo os referidos autores, o parênquima acumula açúcares e, em alguns casos, pigmentos.

Em Smallanthus sonchifolius, todos os canais secretores presentes nas raízes, tanto delgadas quanto tuberosas, são de origem endodérmica. De um modo geral, o processo de formação dos canais secretores em raízes de $S$. sonchifolius é semelhante ao descrito para outras espécies de Asteraceae (Solereder 1908, Guttemberg 1968, Luque et al. 1997, Melo-de-Pinna \& Menezes 2002). Difere, contudo, quanto à localização: enquanto que, na maioria dos registros (Williams 1947, 1954, Luque et al. 1997, Melo-de-Pinna \& Menezes 2002), os canais iniciam-se em oposição ao floema, em S. sonchifolius formam-se em toda a periferia da endoderme.

Deve-se salientar ainda que, em Smallanthus sonchifolius, as células epiteliais dos canais são bem diferenciadas e resultam de divisões desiguais das células produzidas pela endoderme meristemática. Além disso, o número de células epiteliais que delimitam os canais secretores é diferente entre as raízes delgadas e as raízes tuberificadas. Esta variação no número de células já foi ressaltada por Tetley (1925), que afirmou que os canais podem permanecer circundados por quatro células ou, na maioria dos casos, por sucessivas divisões das epiteliais, pode-se chegar a dez células.

Outro aspecto que deve ser destacado é a função secretora das células endodérmicas da raiz de Smallanthus sonchifolius, evidenciada pela presença de gotículas de lipídios no interior dos espaços intercelulares, mesmo antes da formação das células epiteliais. Relato semelhante sobre células endodérmicas secretoras de lipídios foi feito por Luque et al. (1997) em raízes de espécies de Lychnophora (Asteraceae). A habilidade das células endodérmicas para a síntese e secreção de substâncias lipofílicas, além da deposição parietal destas substâncias sob a forma de estria de Caspary, evidenciam a importância da endoderme no metabolismo de substâncias graxas, conforme já ressaltado por Van Fleet (1961).

Agradecimentos - Silvia R. Machado e Nanuza L. Menezes agradecem ao $\mathrm{CNPq}$ as bolsas de produtividade em pesquisa.

\section{Referências bibliográficas}

ANDREATA, R.H.P. \& MENEZES, N.L. 1999. Morfoanatomia do embrião, desenvolvimento pós-seminal e origem do rizóforo de Smilax quinquenervia Vell. (Smilacaceae). Boletim de Botânica, Universidade de São Paulo 18:39-51.

ASAMI, T., KUBOTA, M., MINAMISAWA, K. \& TSUKIHASHI, T. 1989. Chemical composition of yacon, a new root crop from the Andean highlands. Japanese Journal of Soil Science and Plant Nutrition 60:122-126.

ASAMI, T., MINAMISAWA, K., TSUCHIYA, T., KANO, K., HORI, I., OHYAMA, T., KUBOTA, M. \& TSUKIHASHI, T. 1991. Fluctuation of oligofructan contents in tubers of yacon (Polymnia sonchifolia) during growth and storage. Japanese Journal of Soil Science and Plant Nutrition 62:621-627.

BONUCCELI, F.R. 1989. Plantas alimenticias en el antiguo Peru. s.e., Lima.

ESTRELLA, J.E. \& LAZARTE, J.E. 1994. In vitro propagation of jícama (Polymnia sonchifolia Poeppig \& Endlicher): a neglected Andean crop. HortScience 29:331.

FIGUEIREDO-RIBEIRO, R.C., DIETRICH, S.M.C., CARVALHO, M.A.M., VIEIRA, C.C.J., ISEJIMA, E.M., DIAS-TAGLIACOZZO, G.M. \& TERTULIANO, M.F. 1992. As múltiplas utilidades dos frutanos: reserva de carboidratos em plantas nativas do cerrado. Ciência Hoje 14:16-18.

FUKAI, K., MIYAZAKI, S., NANJO, F. \& HARA, Y. 1993. Distribution of carbohydrates and related enzymes activities in yacon (Polymnia sonchifolia). Soil Science and Plant Nutrition 39:567-571.

GOEBEL, K. 1905. Morphologische und biologische bernerkungen. 16. Die knollen der Dioscoreen und die wurzelträger der Selaginellem, organe, welchezwischen wurzeln und sprossen stehen. Flora 95:167-212.

GRAU, A. \& REA, J. 1997. Yacon. Smallanthus sonchifolius (Poepp. \& Endl.) H. Robinson. In Andean roots and tubers: ahipa, arracacha, maca and yacon (M. Hermann \& J. Heller, eds.). International Plant Genetic Resources Institute, Roma, p.200-242.

GUTTEMBERG, H.V. 1968. Der primäre Bau der Angiospermenwurzel. Handbuch der Pflanzenanatomie, Berlin.

HAWKES, J.G. 1989. The domestication of root and tubers in the American tropics. In Foraging and farming: the evolution of plant exploitation (D.R. Harris \& G.C. Hillman, eds.). Unwin Hyman, London, p.481-503.

JOHANSEN, D.A. 1940. Plant microtechnique. McGraw-Hill New York.

KAKUTA, H., SEKI, T., HASHIDOKO, Y. \& MIZUTANI, J. 1992. Ent-kaurenic acid and its related compounds from glandular trichome exudate and leaf extracts of Polymnia sonchifolia. Bioscience Biotechnology and Biochemistry 56:1562-1564. 
KARNOVSKY, M.J. 1965. A formaldehyde-glutaraldehyde fixative of high osmolality for use in electron microscopy. Journal of Cell Biology 27:137A-138A.

LEON, J. 1968. Botanica de los cultivos tropicales. Coleción Libros e Materiales Educativos/IICA, Costa Rica.

LUQUE, R., MENEZES, N.L. \& SEMIR, J. 1997. La función secretora de la endodermis de la raíz de especies de Lychnophora Mart. (Asteraceae). Plantula 1:221-228.

MELO-DE-PINNA, G.F.A. \& MENEZES, N.L. 2002. Vegetative organ anatomy of Ianthopappus corymbosus Roque \& Hind (Asteraceae-Mutisieae). Revista Brasileira de Botânica 25:505-514.

MUELLER, R.J. 1991. Identification of procambium in the primary root of Trifolium pratense (Fabaceae). American Journal of Botany 78:53-62.

NATIONAL RESEARCH COUNCIL. 1989. Lost crops of the incas: little-known of the Andes with promise for worldwide cultivation. National Academy Press, Washington.

NIETO, C.C. 1991. Estudios agronomicos y bromatologicos en jicama (Polymnia sonchifolia Poep. et Endl.). Archivos Latinoamericanos de Nutricion 41:213-221.

O’BRIEN, T.P., FEDER, N. \& MCCULLY, M.E. 1964. Polychromatic staining of plant cell walls by toluidine blue O. Protoplasma 59:368-373.

OHYAMA, T., YASUYOSHI, S., IKARASHI, T., MINAMISAWA, K., KUBOTA, M., TSUKIHASHI, T. \& ASAMI, T. 1990. Composition of storage carbohydrate in tubers of yacon (Polymnia sonchifolia). Soil Science and Plant Nutrition 36:167-171.

ROCHA, D.C. \& MENEZES, N.L. 1997. O sistema subterrâneo de Dioscorea kunthiana Uline ex R. Knuth (Dioscoreaceae). Boletim de Botânica, Universidade de São Paulo 16:1-13.
SAJO, M.G. \& MENEZES, N.L. 1986a. Anatomia do rizóforo de espécies de Vernonia Screb. (Compositae), da Serra do Cipó, MG. Revista Brasileira de Biologia 46:189-196.

SAJO, M.G. \& MENEZES, N.L. 1986b. Origem e crescimento do rizóforo em espécies de Vernonia Screb. (Compositae), da Serra do Cipó, MG. Revista Brasileira de Biologia 46:197-202.

SEAGO JUNIOR, J.L. \& SCHOLEY, A. 1999. Development of the endodermis and hypodermis of Typha glauca Gord. and Typha angustifolia L. roots. Canadian Journal of Botany 77:122-134.

SEAGO JUNIOR, J.L., PETERSON, C.A. \& ENSTONE, D.E. 1999. Cortical ontogeny in roots of the aquatic plant, Hydrocharis morsus-ranae L. Canadian Journal of Botany 77:113-121.

SOLEREDER, H. 1908. Systematic anatomy of dicotyledons. Claredon Press, Oxford.

TETLEY, U. 1925. The secretory system of the roots of the Compositae. The New Phytologist 24:138-161.

VAN FLEET, D.S. 1961. Histochemistry and function of the endodermis. Botanical Review 27:165-220.

WEI, B., HARA, M., YAMAUCHI, R., UENO, Y. \& KATO, K. 1991. Fructooligosaccharides in the tubers of Jerusalem artichoke and yacon. Research Bulletin of the Faculty of Agriculture Gifu University 56:133-138.

WILLIAMS, B.C. 1947. The structure of the meristematic root tip and origin of the primary tissues in the roots of vascular plants. American Journal of Botany 34:455-462.

WILLIAMS, B.C. 1954. Observations on intercellular cannals in root tips with special reference to the Compositae. American Journal of Botany 41:104-106.

ZARDINI, E. 1991. Ethnobotanical notes on "yacon", Polymnia sonchifolia (Asteraceae). Economic Botany 45:72-85. 
